\title{
Treatment of laundry wastewater by solar photo-Fenton process at pilot plant scale
}

\author{
Ana Belén Esteban García ${ }^{1,2} \cdot$ Kacper Szymański $^{3} \cdot$ Sylwia Mozia ${ }^{3}$ (D) José Antonio Sánchez Pérez ${ }^{1,2}$
}

Received: 12 June 2020 / Accepted: 5 October 2020 / Published online: 16 October 2020

(C) The Author(s) 2020

\begin{abstract}
Laundry sector consumes a huge amount of water which is usually discharged as wastewater instead of being reused. The application of biological treatment of laundry wastewater coupled with post-treatment utilizing advanced oxidation processes creates a possibility to recycle water to the washing process. However, the investigations on such systems are very limited. In the present work, a novel approach of post-treatment of laundry wastewater utilizing solar photo-Fenton operated at a pilot scale in a compound parabolic collector (CPC) photoreactor is proposed. Sodium dodecyl sulfate (SDS) was used as a representative of surfactants applied in the laundry system. The effect of feed matrix was investigated using distilled water as a reference matrix and synthetic wastewater simulating the composition of biologically pre-treated laundry wastewater. Different concentrations of $\mathrm{H}_{2} \mathrm{O}_{2}(50-400 \mathrm{mg} / \mathrm{L})$ and ferrous iron $(2.75-10 \mathrm{mg} / \mathrm{L})$ were assayed. For comparison purpose, experiments at neutral $\mathrm{pH}$ using ethylenediamine-N,N'-disuccinic acid (EDDS) as an iron complexing agent were carried out. A high SDS removal efficiency was obtained under both neutral and acidic $\mathrm{pH}$, reaching $89 \%$ and $96 \%$, respectively, in just 8 min. However, the remaining organic load originating from EDDS needs application of further post-treatment steps. Therefore, the solar photo-Fenton operated under acidic $\mathrm{pH}$ was found to be a more promising approach of post-treatment of laundry wastewater aimed at its reuse.
\end{abstract}

Keywords Advanced oxidation process $\cdot$ Surfactants $\cdot$ Sodium dodecyl sulphate $\cdot$ Mineralization $\cdot$ Compound parabolic collector

\section{List of symbols and abbreviations}

AOPs Advanced oxidation processes

CPC Compound parabolic collector

DOC Dissolved organic carbon

DW Distilled water

EDDS Ethylenediamine-N,N'-disuccinic acid

F

HPLC-DAD High-performance liquid chromatography with diode array detector

$\begin{array}{ll}\text { IC } & \text { Inorganic carbon } \\ \text { LOQ } & \text { Limit of quantification } \\ \text { PF } & \text { Photo-Fenton } \\ \text { SDS } & \text { Sodium dodecyl sulphate } \\ \text { SW } & \text { Synthetic wastewater } \\ \text { TOC } & \text { Total organic carbon } \\ \text { UV } & \text { Ultraviolet } \\ V_{i} & \text { Illuminated volume } \\ V_{T} & \text { Total volume }\end{array}$

\section{Introduction}

Laundry wastewater is generated during the washing of clothes at household and industrial scale. Modern laundries use $10 \mathrm{~L}$ of water per $1 \mathrm{~kg}$ of dry clothing, while the water consumption in the old type laundries can be even two to three times higher. Actually, even $90 \%$ of the used water can be discharged as wastewater (Yaseen et al. 2019). The laundry wastewater is characterized mainly by a high content of surfactants commonly used in the washing process, high microbiological load, and a large amount of pollutants, primarily 
fats, dyes, oils, and suspended solids removed from the washed textile items (Braga and Varesche 2014). Such a very complex composition of laundry wastewater requires a special approach to its treatment and application of various techniques. The conventional wastewater treatment methods are usually not efficient enough in the case of laundry wastewater, which causes an environmental pollution problem. For this reason, the development of efficient and cost-effective treatment technology is very important (Patil et al. 2020).

One of the treatment methods used in wastewater treatment plants is a biological process. Biological treatment involves the metabolic activity of living organisms, such as bacteria and fungi, which are present in natural water and soil. The biological processes, however, not always provide satisfactory results, while some contaminants can be toxic for the microorganisms or just non-biodegradable. The presence of nonbiodegradable compounds is observed in the case of laundry wastewater; therefore, before the biologically treated wastewater reaches the environment, it should be polished with other methods (Patil et al. 2020).

The advanced oxidation processes (AOPs) could be promising towards the degradation of persistent contaminants which are not removed during a biological process (Patil et al. 2020). The high efficiency of AOPs is associated with the generation of highly reactive $\mathrm{HO}^{\circ}$ radicals, which can oxidize many organic compounds (Pignatello et al. 2006). Eventually, complete mineralization to $\mathrm{CO}_{2}$, water, and mineral compounds can be obtained. The most extensively studied AOPs are photo-Fenton process (PF) (Ameta et al. 2018), photocatalysis (Amor et al. 2019), $\mathrm{UV} / \mathrm{H}_{2} \mathrm{O}_{2}$ (Miklos et al. 2018), and others (Malato et al. 2009). However, all of these techniques have some disadvantages, mainly high costs due to the high electricity demand (UV lamps) or large amounts of photocatalysts, creating additionally separation problems (Klavarioti et al. 2009). The PF process is one of the most widely used AOPs for the wastewater treatment due to the ability to detoxify and disinfect wastewater streams containing persistent contaminants (Garrido-Cardenas et al. 2020). This technique is environmentally friendly and economically profitable (Umar et al. 2010; Yu et al. 2015); it does not require any catalyst and is relatively simple to perform. Additionally, in case of some recalcitrant pollutants the PF can more effective than other AOPs (Hansson et al. 2012). During the Fenton reaction which involves the combination of $\mathrm{Fe}^{2+}$ and $\mathrm{H}_{2} \mathrm{O}_{2}$ the $\mathrm{HO}^{\circ}$ radical is formed. The reaction rate is enhanced by utilizing UV radiation (photoFenton). In the presence of the light the iron ions are oxidized and reduced cyclically $\left(\mathrm{Fe}^{3+}\right.$ can absorb light yielding hydroxyl radicals and simultaneously its reduction to initial $\mathrm{Fe}^{2+}$ takes place). The cost of implementing this technique to its commercial use can be greatly reduced by using solar energy as a UV light source (Miralles-
Cuevas et al. 2017). From this point of view, the solar PF process can be an effective way to treat laundry wastewater (Yang and Wang 2009). The highly oxidative hydroxyl radicals will be the main species responsible for removal of persistent pollutants from the laundry effluents.

Sodium dodecyl sulphate (SDS) was selected as a model surfactant since it is a commonly applied component of many domestic and industrial detergents, personal hygiene, and cosmetic products, and its use gradually increases year-by-year (Adak et al. 2005). It is estimated that these days, SDS accounts for around $40 \%$ of all detergents consumption, creating a very serious problem in its efficient removal using current techniques. Moreover, this compound exhibits recalcitrant nature and can be harmful to human health and aquatic environment causing irreversible damage on the ecosystem (Malakootian et al. 2016; Collivignarellin et al. 2019). Harmfulness of SDS is primarily due to its accumulation in the environment and organisms, rather not its direct consumption, and cause long lasting effects (Bavcon Kralj et al. 2020; National Center for Biotechnology Information (n.d.) https://pubchem.ncbi. nlm.nih.gov/compound/Sodium-dodecyl-sulfate). Nevertheless, the consumption of this chemical could cause allergic reactions in human (National Center for Biotechnology Information (n.d.) https://pubchem.ncbi. nlm.nih.gov/compound/Sodium-dodecyl-sulfate).

In the subject literature, there are very limited reports on SDS removal in the photo-Fenton process. Some researchers studied the variations of $\mathrm{PF}$ for SDS removal in effluents from carwash (Rahimpour et al. 2020), industrial wastewater (Mirbahoush et al. 2019), textile wastewater (Mahamallik and Pal 2017), soft drink wastewater (Malakootian et al. 2016), and soil washing effluent (Bandala et al. 2013). However, to the best of our knowledge, reports on photoFenton process application to laundry wastewater posttreatment have not been published yet.

The main objective of the presented paper was to investigate the possibility of application of the solar photo-Fenton process for removal of the anionic surfactant sodium dodecyl sulphate from synthetic wastewater of a composition simulating the quality of laundry wastewater after biological treatment. The idea has arisen from our previous works on the treatment of laundry wastewater (Bering et al. 2018a, b; Mozia et al. 2016). During these investigations it was observed that surfactants are not removed efficiently enough during biological treatment and further polishing of the effluent is necessary. One promising approach is the application of AOP such as the solar photo-Fenton system. In the presented research, the effect of process parameters on the degradation efficiency as well as the quality of the product was evaluated. Furthermore, experiments at 
neutral $\mathrm{pH}$ using ethylenediamine-N,N'-disuccinic acid (EDDS) as an iron complexing agent were carried out.

\section{Materials and Methods}

\section{Chemicals and aqueous matrices}

Sodium dodecyl sulphate (SDS, $\mathrm{NaC}_{12} \mathrm{H}_{25} \mathrm{SO}_{4}, 98.5 \% \mathrm{w} / \mathrm{w}$ ), tetrabutylammonium bisulphate $(97 \%$, w/w), ethylenediamine-N,N'-disuccinic acid (EDDS, 35\%, w/v), titanium(IV) oxysulphate $(1.9 \%, \mathrm{w} / \mathrm{v})$, ascorbic acid $(99 \%$, $\mathrm{w} / \mathrm{w})$, sodium bisulphite $(40 \% \mathrm{w} / \mathrm{v})$, and formic acid $(95 \%$, w/v) were supplied by Sigma-Aldrich. Chloroform (HPLC grade), and sulphuric acid $(98 \%, \mathrm{w} / \mathrm{v})$ were acquired from J.T. Baker. 1,10-phenantroline $(99 \% \mathrm{w} / \mathrm{w})$, acetic acid $(99.7 \% \mathrm{w} / \mathrm{v})$, hydrochloric acid $(37 \% \mathrm{w} / \mathrm{v})$, hydrogen peroxide $(33 \% \mathrm{w} / \mathrm{v})$, acetonitrile (HPLC grade), ferrous sulphate heptahydrated $\left(\mathrm{FeSO}_{4} \cdot 7 \mathrm{H}_{2} \mathrm{O}\right)$, and ferric sulphate hydrate $(75 \% \mathrm{w} / \mathrm{w})$ were obtained from Panreac. Sodium formate $(99 \%, \mathrm{w} / \mathrm{w})$ was supplied by Merck Millipore (Darmstadt, Germany), while methylene blue $(98 \%$, w/w) was purchased from Chempur (Poland). Ultrapure water was produced with a Millipore Direct-Q® Ultrapure Water System (Bedford, MA, USA). The constituents for preparing synthetic laundry wastewater (SW) were bactopeptone $(25 \mathrm{mg} / \mathrm{L}, \mathrm{BD}-\mathrm{Difco})$ and meat extract (20 mg/L, Biolife); urea ( $30 \mathrm{mg} / \mathrm{L})$, calcium chloride $(140 \mathrm{mg} / \mathrm{L})$, and dipotassium phosphate $(5 \mathrm{mg} / \mathrm{L})$ supplied by Panreac; and magnesium sulphate $(50 \mathrm{mg} / \mathrm{L})$ and ammonium sulphate $(5 \mathrm{mg} / \mathrm{L}$ ) obtained from Sigma Aldrich. The composition of the synthetic wastewater with reference to total organic carbon and inorganic salts content represented the quality of the real biologically treated laundry wastewater investigated previously (Bering et al. 2018a, b; Mozia et al. 2016).

\section{Experimental set-up}

All PF assays were carried out at pilot plant scale in a tubular photo-reactor equipped with a compound parabolic collector (CPC; Fig. 1), under solar natural radiation in the Solar Energy Research Center (CIESOL, University of Almería, Spain). The solar plant consisted of two twin photo-reactors with borosilicate glass tubes $(5-\mathrm{cm}$ diameter) installed on a southfacing tilted platform at a local latitude of $37^{\circ}$ (Cabrera Reina et al. 2018). This plant allows conducting two experiments simultaneously in the same conditions. The total illuminated surface of each photo-reactor was $0.42 \mathrm{~m}^{2}$, while the total $\left(V_{T}\right)$ and the illuminated volume $\left(V_{i}\right)$ were $9 \mathrm{~L}$ and $4.8 \mathrm{~L}$, respectively. Assays were run in a batch mode, and the aqueous solutions were recirculated in the system through centrifugal pumps with a water flow rate of $22 \mathrm{~L} / \mathrm{min}$ and a mixing time around $7 \mathrm{~min}$. UVA radiation, temperature, and $\mathrm{pH}$ were

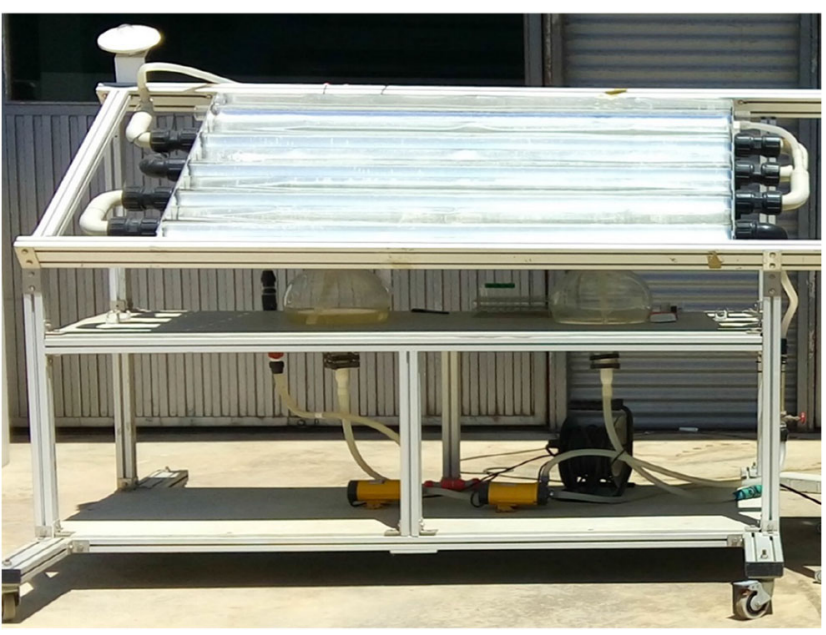

Fig. 1 Pilot tubular photo-reactor equipped with a compound parabolic collector (CPC) situated in Solar Energy Research Center (CIESOL, University of Almería, Spain)

monitored by a UV radiometer (Delta Ohm LP UVA $02 \mathrm{AV}$, spectral range from 327 to $384 \mathrm{~nm}$ ), a temperature probe (Crison 6050), and a pH probe (Crison 5335), respectively. Data measured online were acquired by a data acquisition card (LabJack U12) connected to a computer. The solar experiments were performed at noon and the average value of the global UVA irradiance and temperature were $26 \pm 2 \mathrm{~W} / \mathrm{m}^{2}$ and $29.0 \pm 0.8^{\circ} \mathrm{C}$, respectively.

In all assays, the $\mathrm{pH}$ was adjusted at 2.8 with sulphuric acid $(1 \mathrm{M})$ and the solar exposition time was $120 \mathrm{~min}$. Firstly, the glass tubes and twin photo-reactors were covered with black canvas and aluminium paper, respectively. Having done that, the two CPC tanks were loaded with the aqueous matrix and recirculated during $10 \mathrm{~min}$ for mixing. After that, hydrogen peroxide was added and mixed for $10 \mathrm{~min}$. A control sample was collected for checking the initial oxidant concentration. Consecutively, the system was supplemented with ferrous iron and uncovered, starting the PF reaction. In case of the dark Fenton process the system remained covered during the whole experiment. Samples were directly taken from CPC reactor every $2 \mathrm{~min}$ during the first $10 \mathrm{~min}$, every $5 \mathrm{~min}$ during the following $10 \mathrm{~min}$, and later samples were collected every $10 \mathrm{~min}$. Hydrogen peroxide, dissolved iron, and SDS concentrations were analysed in each sample. In addition, the mineralization degree of SDS was assessed in all samples.

Two experimental sets in outdoor conditions with two aqueous solutions (distilled water (DW) and synthetic wastewater (SW)) were conducted with $40 \mathrm{mg} / \mathrm{L}$ and $2 \mathrm{mg} / \mathrm{L}$ of SDS. The concentration of SDS, being a representative of anionic surfactants, was selected on a basis of the previous research on treatment of real laundry wastewater (Mozia et al. 2016; Bering et al. 2018a, b). Different concentrations of hydrogen peroxide $(400,200,100$, and $50 \mathrm{mg} / \mathrm{L})$ and ferrous iron $(10,5.5$, and $2.75 \mathrm{mg} / \mathrm{L})$ were assayed. Fenton $(\mathrm{F})$ 
experiments were carried out using the SDS concentration of 2 $\mathrm{mg} / \mathrm{L}$ as a blank. Additionally, experiments at neutral $\mathrm{pH}$ were carried out with $\mathrm{Fe}^{3+}$ :EDDS complex. The concentration of $\mathrm{Fe}^{3+}$ was $5.5 \mathrm{mg} / \mathrm{L}$ and the molar ratio of $\mathrm{Fe}^{3+}$ :EDDS was 1:1.

\section{Analytical determinations}

Before the quantification of hydrogen peroxide and ferrous iron concentrations, the samples were filtered through $0.2-\mu \mathrm{m}$ nylon filters (Merck Millipore $\AA$ ). The absorbance of filtered samples with $\mathrm{H}_{2} \mathrm{O}_{2}$ and dissolved ferrous iron were determined at $410 \mathrm{~nm}$ with titanium(IV) oxysulfate reagent and 1,10 phenanthroline solution at $510 \mathrm{~nm}$ using standard methods, DIN $38402 \mathrm{H} 15$ (LOQ was $2.9 \cdot 10^{-2} \mathrm{mM}$ and SD was $4 \cdot 10^{-3} \mathrm{mM}$ ) and ISO 6332 (LOQ was $4.5 \cdot 10^{-3}$ $\mathrm{mM}$ and SD was $6.1 \cdot 10^{-4} \mathrm{mM}$ ), respectively. The $\mathrm{H}_{2} \mathrm{O}_{2}$ and dissolved ferrous iron concentrations were obtained on the calibration curves. The concentration of sodium dodecyl sulphate was measured by colorimetric method adapted from (Koga et al. 1999) using methylene blue and chloroform. The detection limit of this method was $0.1 \mathrm{mg} / \mathrm{L}$. The $\mathrm{Fe}^{3+}$ EDDS complex was determined by a 1200 Series system liquid chromatography with diode array detector (UHPLCDAD) from Agilent Technologies (Waldbronn, Germany) according to Soriano-Molina et al. (2019). Dissolved organic carbon (DOC) and dissolved inorganic carbon (IC) were measured using filtered samples, with a Shimadzu-V CPH TOC analyser, which LOQ was $1 \mathrm{mg} / \mathrm{L}$.

\section{Results and discussion}

\section{Effect of iron concentration on SDS removal}

The first experimental set was designed in order to select the most effective iron concentration to remove and mineralize $2 \mathrm{mg} \mathrm{SDS} / \mathrm{L}$ in a synthetic wastewater by solar photoFenton at acidic pH (2.8) using a CPC reactor. Results are shown in Fig. 2. In general, at higher iron content the process proceeds with higher efficiency due to (i) a faster regeneration of $\mathrm{Fe}^{2+}$ which leads to its better availability for hydroxyl radical production from $\mathrm{H}_{2} \mathrm{O}_{2}$ and (ii) a better utilization of $\mathrm{H}_{2} \mathrm{O}_{2}$, which is mainly consumed in the reaction of $\mathrm{HO}^{\circ}$ formation, not in side reactions. Furthermore, at higher iron concentration, the amount of $\mathrm{H}_{2} \mathrm{O}_{2}$ required for the same degradation degree is lower (Zapata et al. 2009). Concerning SDS removal, Fig. 2a shows an initial drop by Fenton process in the first few minutes $(2 \mathrm{~min}$ ) due to the addition of the catalyst in the form of ferrous iron following Reaction (1). This effect produces around $58 \%, 84 \%$, and $94 \%$ of SDS removal for $2.75 \mathrm{mg} \mathrm{Fe} / \mathrm{L}, 5.5 \mathrm{mg} / \mathrm{L}$, and $10 \mathrm{mg} / \mathrm{L}$ of ferrous iron added, respectively. This means the Fenton effect is rather important in pollutant removal only if high iron concentrations are used.

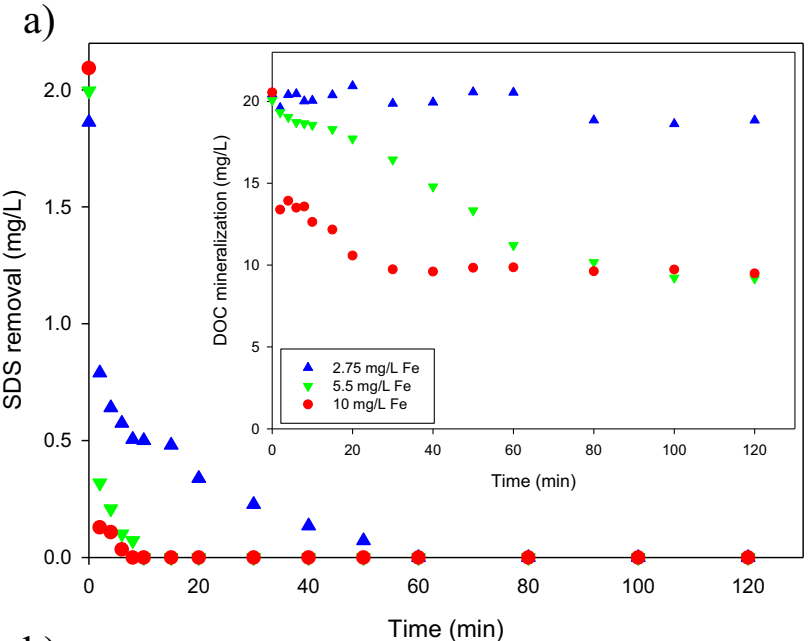

b)

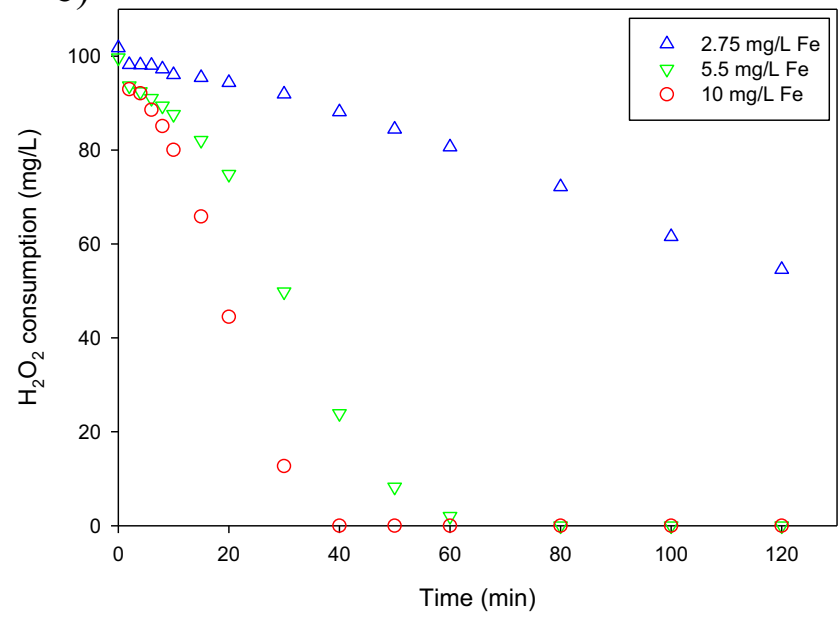

Fig. 2 Effect of iron concentration (10, 5.5, and $2.75 \mathrm{mg} / \mathrm{L})$ with $100 \mathrm{mg} /$ $\mathrm{L} \mathrm{H}_{2} \mathrm{O}_{2}$ in synthetic secondary effluent (SW) during solar PF process on a SDS removal and DOC mineralization (inserted figure) of $2 \mathrm{mg} \mathrm{SDS} / \mathrm{L}$. b Consumption of hydrogen peroxide

After this first reaction stage, ferric iron generated in Reaction (1) is reduced via solar radiation (Reaction (2)) to ferrous iron, thus closing the redox iron cycle and the degradation becomes progressive. Reaction (1) is independent of UV-light and only depends on iron and hydrogen peroxide concentrations. After the initial degradation, SDS profile followed a pseudo-first order rate although could not be appreciated, since its degradation was very fast. After 10 min of the photo-Fenton treatment, more than $98 \%$ of SDS was removed with the highest concentration of ferrous iron $(10 \mathrm{mg} / \mathrm{L})$, and for $5.5 \mathrm{mg} / \mathrm{L}$ was equal to $97 \%$. These results demonstrated that increasing iron concentration did not produce a substantial increase in the degradation rate of SDS. Nevertheless, $60 \mathrm{~min}$ were needed with $2.75 \mathrm{mg} \mathrm{Fe}^{2+} / \mathrm{L}$ for achieving the SDS removal below the detection limit.

$\mathrm{Fe}^{2+}+\mathrm{H}_{2} \mathrm{O}_{2} \rightarrow \mathrm{Fe}^{3+}+\mathrm{HO}^{-}+\mathrm{HO}^{\circ}$
$\mathrm{Fe}^{3+}+\mathrm{H}_{2} \mathrm{O}+\mathrm{hv} \rightarrow \mathrm{Fe}^{2+}+\mathrm{HO}^{\circ}+\mathrm{H}^{+}$ 
In the inset of Fig. 2a, the profiles of DOC mineralization are shown. It should be noted here that DOC corresponds to both the organic contaminants present in the synthetic wastewater (i.e., peptone and components of meat extract) and the model surfactant. Since the hydroxyl radicals are consumed in the oxidation of all the organic substances, the mineralization of SDS is affected by the presence of other organic contaminants. The DOC mineralization proceeded up to $30 \mathrm{~min}$ and $60 \mathrm{~min}$ with 10 and $5.5 \mathrm{mg} \mathrm{Fe}^{2+} / \mathrm{L}$, respectively, stopping later due to the lack of hydrogen peroxide. In both cases the DOC content at the end of experiment amounted to ca. $10 \mathrm{mg} / \mathrm{L}$; however, the initial stage of mineralization was very different. In the case of the highest concentration of ferrous iron a significant decrease of DOC content just at the beginning of the irradiation was found, while the changes observed for $5.5 \mathrm{mg}$ $\mathrm{Fe}^{2+} / \mathrm{L}$ were significantly slower. That corresponds to the initial drop by Fenton process discussed above and confirms the importance of high iron concentration during this stage. At the lowest concentration of ferrous iron $\left(2.75 \mathrm{mg} \mathrm{Fe}^{2+} / \mathrm{L}\right)$ the mineralization was not effective and the DOC content remained almost unchanged during $2 \mathrm{~h}$ of the process realization.

The evolution of hydrogen peroxide concentration with time is shown in Fig. 2b. At first glance, it can be seen that the effects observed for SDS degradation and DOC mineralization are well reflected in hydrogen peroxide consumption. When 5.5 and $10 \mathrm{mg} \mathrm{Fe}^{2+} / \mathrm{L}$ were used, the hydrogen peroxide consumption was $>99 \%$ after 60 and $40 \mathrm{~min}$, respectively. This is consistent since $\mathrm{H}_{2} \mathrm{O}_{2}$ consumption rate is proportional to the concentration of the catalyst. Nevertheless, $50 \% \mathrm{H}_{2} \mathrm{O}_{2}$ was still in the system at the end of the treatment with $2.75 \mathrm{mg}$ $\mathrm{Fe}^{2+} / \mathrm{L}$.

Moreover, based on the results presented in Fig. $2 \mathrm{~b}$ it can be seen that in the case of $2.75 \mathrm{mg} \mathrm{Fe} e^{2+} / \mathrm{L}$ the $\mathrm{H}_{2} \mathrm{O}_{2}$ consumption rate is very low $(0.37 \mathrm{mg} / \mathrm{L} \mathrm{min})$. This is because at low ferrous iron content the radiation was utilized in a small degree, which resulted in a limited $\mathrm{H}_{2} \mathrm{O}_{2}$ consumption. However, for higher ferrous iron concentration when photons reaching reactor surface are fully absorbed, the $\mathrm{H}_{2} \mathrm{O}_{2}$ consumption rates are proportional to the $\mathrm{Fe}$ content, and reach $1.8 \mathrm{mg} / \mathrm{L} \mathrm{min}$ for $5.5 \mathrm{mg} \mathrm{Fe}{ }^{2+} / \mathrm{L}$ and $3.0 \mathrm{mg} / \mathrm{L} \mathrm{min}$ for $10 \mathrm{mg}$ $\mathrm{Fe}^{2+} / \mathrm{L}$. Calculating the ratio of initial $\mathrm{Fe}^{2+}$ concentration (5.5/ $10=0.55)$ and the ratio of $\mathrm{H}_{2} \mathrm{O}_{2}$ consumption rate $(1.8 / 3.0=$ $0.6)$ in both experiments, it can be found that they are closely similar.

\section{Effect of $\mathrm{H}_{2} \mathrm{O}_{2}$ concentration on SDS removal}

In order to study the effect of hydrogen peroxide concentration on SDS removal and DOC mineralization, a second experimental set was carried out using $5.5 \mathrm{mg} / \mathrm{L}$ of $\mathrm{Fe}^{2+}$. Such a concentration was selected because at both higher iron contents the SDS was almost completely removed in $10 \mathrm{~min}$ of the process. The effect of the Fenton reaction in these conditions was studied as a blank. The results show that SDS degradation rate by solar photo-Fenton is fast, reaching > 99\% of removal with the four hydrogen peroxide concentrations in $15 \mathrm{~min}$ of the treatment time (Fig. 3a). The first step is always marked by a high and fast oxidation of the compounds due to the initial reaction of ferrous iron with hydrogen peroxide (Reaction (1)) (Fenton effect). This is reflected in the similar degree of SDS removal (Fig. 3a) for both the Fenton and the photo-Fenton processes at the very beginning of the experiments. However, subsequently, the decomposition of SDS proceeded significantly faster during the processes involving UV irradiation, even for the lowest dose of hydrogen peroxide (i.e., $50 \mathrm{mg} / \mathrm{L}$ ). Hydroxyl radicals formed under the UV radiation took part in the direct degradation of SDS and the oxidation of other organic compounds present in the wastewater (such as peptone or components of meat extract,

a)

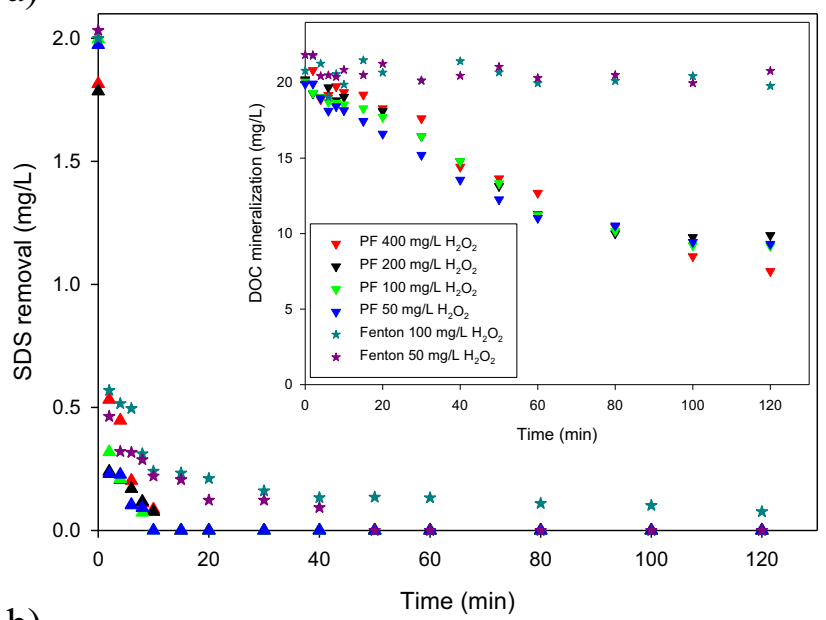

b)

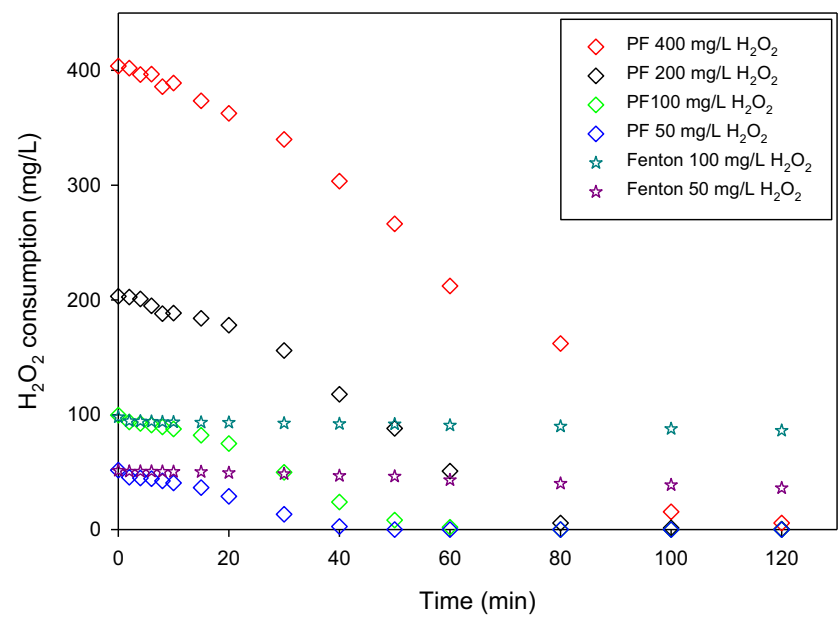

Fig. 3 Fenton and solar photo-Fenton (PF) processes applied on $2 \mathrm{mg}$ $\mathrm{SDS} / \mathrm{L}$ with $5.5 \mathrm{mg} \mathrm{Fe}^{2+} / \mathrm{L}$ and four concentrations of hydrogen peroxide in the synthetic secondary effluent (SW). a Removal of SDS and DOC mineralization (inserted figure). b Hydrogen peroxide consumption 
and by-products formed during decomposition), as well as in the redox cycle with the participation of $\mathrm{Fe}^{3+}$ ions. Hence, a more effective SDS removal and DOC degradation after 120 min of experiment took place in the case of the PF, achieving approximately $50 \%$ of DOC mineralization for $\mathrm{H}_{2} \mathrm{O}_{2}$ doses in the range of $50-200 \mathrm{mg} / \mathrm{L}$, and in the case of the highest concentration of $\mathrm{H}_{2} \mathrm{O}_{2}$ (i.e., $400 \mathrm{mg} / \mathrm{L}$ ) still some low progress of DOC removal was observed. Regarding the DOC profiles during the dark Fenton process, no noticeable changes of the concentration were found in both cases, demonstrating that the increase of $\mathrm{H}_{2} \mathrm{O}_{2}$ dose had no positive influence on the improvement of the mineralization (inset of Fig. 3a). These results revealed that the efficiency of the Fenton process in laundry wastewater treatment is significantly lower compared with that of the photo-Fenton system. This is because in the Fenton process the hydroxyl radicals are formed only during the oxidation of $\mathrm{Fe}^{2+}$ to $\mathrm{Fe}^{3+}$ represented by Reaction (1), while during the solar photo-Fenton process a continuous generation of $\mathrm{HO}^{\circ}$ proceeds (Reaction (2)).

In Fig. 3b, the curves representing $\mathrm{H}_{2} \mathrm{O}_{2}$ consumption with time are compared. In general, the consumption of this oxidant can be adjusted to the pseudo-first order kinetics. This can be observed in Fig. 3b, when $400 \mathrm{mg}_{2} \mathrm{O}_{2} / \mathrm{L}$ are used the consumption rate is $3.6 \mathrm{mg} / \mathrm{L} \mathrm{min}$, while with $50 \mathrm{mg} / \mathrm{L}$ it is 1.2 $\mathrm{mg} / \mathrm{L}$ min. Hydrogen peroxide was completely consumed in the system after $120 \mathrm{~min}$ of the treatment only in the case of the initial concentration equal to 50 and $100 \mathrm{mg} \mathrm{H}_{2} \mathrm{O}_{2} / \mathrm{L}$, while at the highest dose of the oxidant the final value was about $5 \mathrm{mg} / \mathrm{L}$.

In the Fenton process, the slower regeneration of ferrous iron in the absence of light resulted in an insignificant hydrogen peroxide consumption (Fig. 3b). Thus, fewer hydroxyl radicals were yielded and DOC concentration did not change during the process (inset of Fig. 3a). Nevertheless, the small amounts of radicals generated were enough to oxidize the SDS, but more slowly than in the solar photo-Fenton process (Fig. 3a).

\section{Effect of the aqueous matrix composition on SDS removal}

In view of the above results and to demonstrate that the SDS is mineralized, different experiments were carried out in two matrices, synthetic wastewater (SW) and distilled water (DW) with the highest concentrations of hydrogen peroxide, 400 and $200 \mathrm{mg} / \mathrm{L}$ and SDS concentration increased to $40 \mathrm{mg} /$ $\mathrm{L}$, to take into account the effect of organic matter concentration on the photo-Fenton process performance (Ballesteros Martín et al. 2009). As can be observed in Fig. 4a, the SDS oxidation was not influenced by the concentration of $\mathrm{H}_{2} \mathrm{O}_{2}$ in SW obtaining the same SDS degradation, $>99 \%$, in $60 \mathrm{~min}$ of the treatment with both hydrogen peroxide concentrations. However, the treatment time to remove SDS below the a)

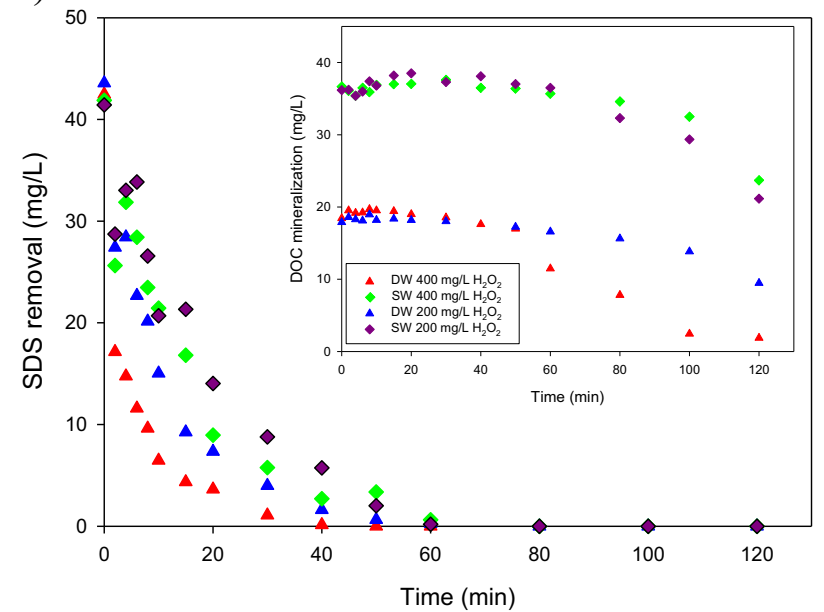

b)

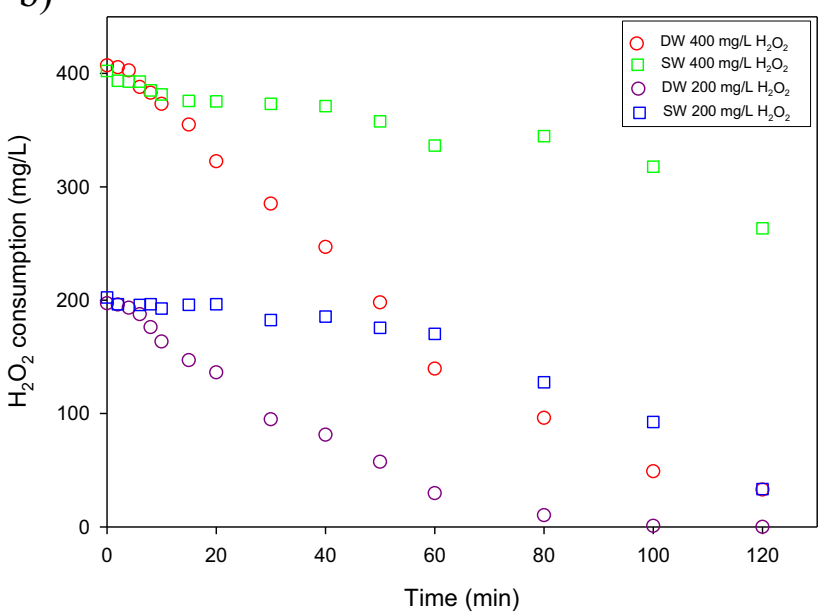

Fig. 4 Effect of solar photo-Fenton process on removal of $40 \mathrm{mg}$ SDS/L with $5.5 \mathrm{mg} \mathrm{Fe} \mathrm{m}^{2+} / \mathrm{L}$ and two concentrations of hydrogen peroxide: 400 $\mathrm{mg} / \mathrm{L}$ and $200 \mathrm{mg} / \mathrm{L}$, using distilled water (DW) and synthetic secondary effluent (SW). a SDS removal and DOC mineralization (inserted figure) of $40 \mathrm{mg} \mathrm{SDS} / \mathrm{L}$. b Consumption of hydrogen peroxide

detection limit is shorter in DW (40 min with $400 \mathrm{mg} \mathrm{H}_{2} \mathrm{O}_{2}$ / L) than in SW $(60 \mathrm{~min})$ due to the lack of the additional organic matter. Accordingly, the hydroxyl radicals generated during the photo-Fenton process attacked the model surfactant solely. The DOC mineralization is shown in the inset of Fig. 4a. During the first $60 \mathrm{~min}$, the SDS is mainly oxidized giving place to an initial shoulder in the DOC removal profile. The process of DOC mineralization begins when a complete removal of SDS is reached, regardless of the applied matrix. In the case of SW, the mineralization percentage is similar with both hydrogen peroxide concentrations (around 40\%), whereas this percentage increases with $400 \mathrm{mg} \mathrm{H}_{2} \mathrm{O}_{2} / \mathrm{L}$ in DW achieving the total mineralization below the detection limit in $120 \mathrm{~min}$ of the treatment process. A non-substantial difference between DOC mineralization profiles in SW for the two $\mathrm{H}_{2} \mathrm{O}_{2}$ concentrations (inset in Fig. 4a) can be attributed to the presence of various and complex organic compounds 
originating from peptone and meat extract (Cabrera Reina et al. 2018). These substances could hinder the DOC mineralization, even for such high $\mathrm{H}_{2} \mathrm{O}_{2}$ concentration. This is because of the non-selective character of hydroxyl radicals, which can react with various organic species. In case of DW, only a decomposition of high amount of SDS and its further mineralization took place.

Based on the changes of $\mathrm{H}_{2} \mathrm{O}_{2}$ concentration in DW and SW presented in Fig. 4b, it can be found that the consumption of $\mathrm{H}_{2} \mathrm{O}_{2}$ in DW was greater than in $\mathrm{SW}$, which corresponds well with the DOC mineralization profile (Fig. 4a). The rates of $\mathrm{H}_{2} \mathrm{O}_{2}$ removal in DW amounted to 2.9 and $3.9 \mathrm{mg} / \mathrm{L} \mathrm{min}$ for 200 and $400 \mathrm{mgH}_{2} \mathrm{O}_{2} / \mathrm{L}$, respectively, while in the case of SW they were equal to 0.5 and $0.7 \mathrm{mg} / \mathrm{L}$ min only. It is also worth noting that the consumption of hydrogen peroxide in DW was similar to that observed in the experiments presented in Fig. 3, in which the initial DOC concentration was comparable (about $20 \mathrm{mg} / \mathrm{L}$ ). In case of $200 \mathrm{mgH}_{2} \mathrm{O}_{2} / \mathrm{L}$ the consumption rates were 2.9 and $2.5 \mathrm{mg} / \mathrm{L}$ min, respectively, while for $400 \mathrm{mgH}_{2} \mathrm{O}_{2} / \mathrm{L}$ they amounted to 3.6 and $3.9 \mathrm{mg} / \mathrm{L} \mathrm{min}$, respectively. These results indicate that the type of organic contaminants (i.e., SDS solely (Fig. 4) or SDS in SW (Fig. 3)) was not important, confirming the non-selective character of hydroxyl radicals participating in the mineralization process.

\section{A comparison of SDS removal under acidic and neutral pH}

The main disadvantage of the photo-Fenton process is a need of acidification of the reaction medium $(\mathrm{pH}<3)$ in order to operate the system with high efficiency. To overcome this drawback the application of EDDS under neutral $\mathrm{pH}$ can be considered. This chemical is biodegradable and safe for the environment; therefore, its utilization as the iron complexing agent for the PF process could be a practical solution (Arzate et al. 2020; Hinojosa Guerra et al. 2019). Hence, assays at neutral $\mathrm{pH}$ using $\mathrm{Fe}^{3+}$-EDDS complex were additionally carried out. To easy compare the results, the selected process conditions reflected those in the first set of experiments (Fig. 2), i.e., concentration of hydrogen peroxide was $100 \mathrm{mg} / \mathrm{L}$, while that of SDS amounted to $2 \mathrm{mg} / \mathrm{L}$. The $\mathrm{Fe}^{3+}$ :EDDS molar ratio equal to 1:1 was selected on a basis of literature data. For example, Arzate et al. (2020) reported that the removal of contaminants of emerging concern from secondary effluents of municipal wastewater treatment plant through the solar PF at neutral $\mathrm{pH}$ was more efficient at 1:1 molar ratio of $\mathrm{Fe}^{3+}$ :EDDS and hydraulic residence time (HRT) of $20 \mathrm{~min}$ than at 1:2 ratio and HRT of $40 \mathrm{~min}$.

As can be observed in Fig. 5, the solar photo-Fenton was able to remove ca. $89 \%$ of SDS and mineralize $13 \%$ of DOC during first $8 \mathrm{~min}$, corresponding to the time in which the complex was present in the solution. Later, due to $\mathrm{Fe}^{3+}$ -

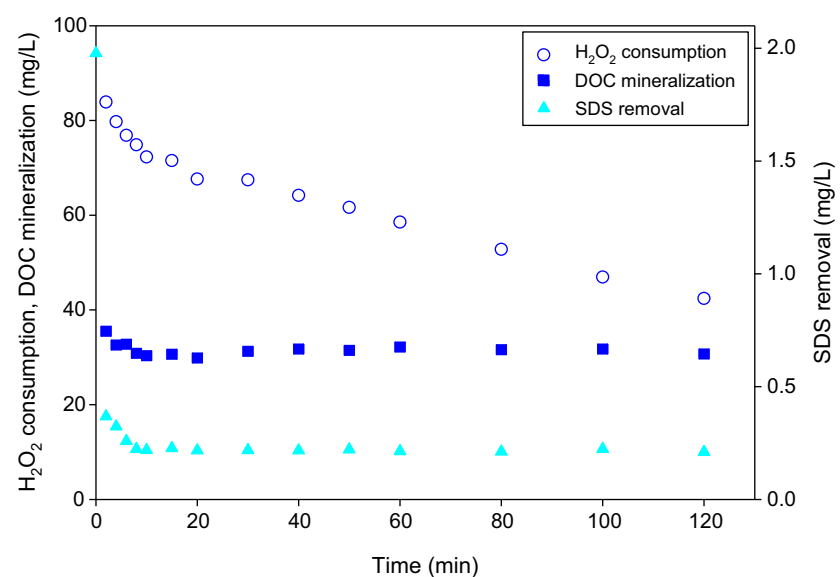

Fig. 5 Solar $\mathrm{PF}$ at neutral $\mathrm{pH}$ for $2 \mathrm{mg} \mathrm{SDS} / \mathrm{L}$ in synthetic secondary effluent (SW) with $100 \mathrm{mg} \mathrm{H}_{2} \mathrm{O}_{2} / \mathrm{L}$ and $5.5 \mathrm{mg} / \mathrm{L}$ of $\mathrm{Fe}^{3+}$ :EDDS

EDDS photodecomposition, the degradation stopped and the values of both parameters remained unchanged up to the end of the process. The presence of $\mathrm{Fe}^{3+}$-EDDS contributed to a higher rate of $\mathrm{H}_{2} \mathrm{O}_{2}$ consumption $(1.50 \mathrm{mg} / \mathrm{L}$ min) during the lifetime of the complex (less than $10 \mathrm{~min}$ ) compared with the second stage of the process. The decomposition of the complex caused a decrease in the $\mathrm{H}_{2} \mathrm{O}_{2}$ consumption rate to 0.27 $\mathrm{mg} / \mathrm{L}$ min (Fig. 5). The residual $\mathrm{H}_{2} \mathrm{O}_{2}$ concentration was very high and amounted to $40 \mathrm{mg} / \mathrm{L}$. The obtained results revealed the possibility of SDS decomposition; however, the DOC mineralization was on a very low level. Nonetheless, opposite to the conventional photo-Fenton, the complete SDS removal was not achieved (Fig. 5). In the case of PF process, even for the lowest hydrogen peroxide concentration, the SDS removal below the detection limit was noted after $8 \mathrm{~min}$ (Fig. 3a). Also, mineralization of DOC was more efficient in PF. For the same $\mathrm{H}_{2} \mathrm{O}_{2}$ dose $(100 \mathrm{mg} / \mathrm{L})$ it systematically proceeded through 80 $\mathrm{min}$, and after $120 \mathrm{~min}$ of the process it exceeded 50\% (Fig. 3a).

Despite a relatively high rate of SDS decomposition, a disadvantage of the application of the $\mathrm{Fe}^{3+}$-EDDS complex is a high concentration of organic load in the solution resulting from EDDS addition. In case of utilization of this type of AOP for post-treatment of laundry wastewater aimed at its reuse in the laundry cycle, an additional treatment step aimed at the removal of the organic contaminants must be considered.

\section{Conclusions}

The removal of the anionic surfactant, sodium dodecyl sulphate, from a synthetic secondary effluent of a laundry wastewater treatment system in a pilot scale solar photo-Fenton plant was investigated. The results indicated that when the initial surfactant concentration was 2 $\mathrm{mg} / \mathrm{L}$ the most beneficial PF operational conditions under solar light were $5.5 \mathrm{mgFe}^{2+} / \mathrm{L}$ and $100 \mathrm{mgH}_{2} \mathrm{O}_{2} / \mathrm{L}$. 
For these parameters the SDS degradation exceeded $99 \%$ in $15 \mathrm{~min}$ and the DOC mineralization reached about $50 \%$ in $120 \mathrm{~min}$ of irradiation. The investigations on the influence of the aqueous matrix composition revealed that decomposition of $40 \mathrm{mg} / \mathrm{L}$ SDS in distilled water was faster than in the synthetic wastewater, although in both cases the concentration of the surfactant decreased below the detection limit in $60 \mathrm{~min}$ or less. On the opposite, DOC mineralization was significantly less effective in the case of the sewage due to the presence of other organic contaminants competing with SDS for the hydroxyl radicals. The DOC mineralization at $5.5 \mathrm{mgFe}^{2+} / \mathrm{L}$ and $400 \mathrm{mgH}_{2} \mathrm{O}_{2} / \mathrm{L}$ reached almost $100 \%$ when distilled water was used as a matrix and only about $40 \%$ in the case of the synthetic sewage. The consumption of $\mathrm{H}_{2} \mathrm{O}_{2}$ was greater in DW compared with SW and corresponded well with changes of DOC concentration. Moreover, it was found that the $\mathrm{H}_{2} \mathrm{O}_{2}$ consumption rates in various solutions containing similar DOC amount but of different origin (i.e., associated solely with SDS dissolved in DW or related to various organic contaminants in the SW) were similar, which confirmed the non-selective character of hydroxyl radicals participating in the mineralization process.

The analysis of SDS removal under dark Fenton conditions revealed that this process is inefficient in laundry wastewater treatment. Moreover, for comparison purpose the treatment of the synthetic wastewater was also realized at neutral $\mathrm{pH}$ with application of EDDS as the iron complexing agent. The applied conditions allowed to decompose SDS with good efficiency ( $89 \%$ in $8 \mathrm{~min}$ ), although slightly lower than under acidic conditions $(96 \%)$. However, a disadvantage is that the effluent still needs post-treatment due to the presence of high DOC content arising from EDDS addition, which excludes it from direct reuse in the laundry process.

The experiments revealed a great potential of the solar photo-Fenton realized at acidic $\mathrm{pH}$ in terms of posttreatment of biologically pre-treated laundry wastewater. Future work should be focused on finding the conditions for improved mineralization of DOC and removal of iron in order to create a possibility of recycling of the post-treated effluent to the laundry process.

Acknowledgements We thank the Solar Energy Research Centre (CIESOL) for providing access to its installations and the support of its scientific and technical staff.

Authors' contributions $\mathrm{ABEG}$ and $\mathrm{KSz}$ designed the experiments, conducted the research, and analysed the data. SM and JASP devised the project and the main conceptual ideas and aided in interpreting the results. All authors contributed to writing of the manuscript. JASP acquired the financial support for the project leading to this publication. All authors read and approved the final manuscript.
Funding This work was supported by SFERA-III project (Grant Agreement No 823802).

Data availability The datasets used and/or analysed during the current study are available from the corresponding author on reasonable request.

\section{Compliance with ethical standards}

Competing interests The authors declare that they have no competing interests

Ethics approval and consent to participate Not applicable

Consent for publication Not applicable

Open Access This article is licensed under a Creative Commons Attribution 4.0 International License, which permits use, sharing, adaptation, distribution and reproduction in any medium or format, as long as you give appropriate credit to the original author(s) and the source, provide a link to the Creative Commons licence, and indicate if changes were made. The images or other third party material in this article are included in the article's Creative Commons licence, unless indicated otherwise in a credit line to the material. If material is not included in the article's Creative Commons licence and your intended use is not permitted by statutory regulation or exceeds the permitted use, you will need to obtain permission directly from the copyright holder. To view a copy of this licence, visit http://creativecommons.org/licenses/by/4.0/.

\section{References}

Adak A, Bandyopadhyay M, Pal A (2005) Removal of anionic surfactant from wastewater by alumina: a case study. Colloids Surf A Physicochem Eng Asp 254:165-171. https://doi.org/10.1016/j. colsurfa.2004.12.004

Ameta R, Chohadia AK, Jain A, Punjabi PB (2018) Advanced oxidation processes for waste water treatment Chapter 3-Fenton and photoFenton processes. In: Ameta SC, Ameta R (eds) Advanced oxidation processes for waste water treatment. Emerging Green Chemical Technology. Print ISBN: 9780128105252. February 21, 2018. https://doi.org/10.1016/B978-0-12-810499-6.00003-6.

Amor C, Marchão L, Lucas MS, Peres JA (2019) Application of advanced oxidation processes for the treatment of recalcitrant agroindustrial wastewater: a review. Water 11(2):205. https://doi.org/ $10.3390 /$ w1 1020205

Arzate S, Campos-Mañas MC, Miralles-Cuevas S, Agüera A, García Sánchez JL, Sánchez Pérez JA (2020) Removal of contaminants of emerging concern by continuous flow solar photo-Fenton process at neutral pH in open reactors. J Environ Manag 261:110265. https:// doi.org/10.1016/j.jenvman.2020.110265

Ballesteros Martín MM, Sánchez Pérez JA, García Sánchez JL, Casas López JL, Malato Rodríguez S (2009) Effect of pesticide concentration on the degradation process by combined solar photo-Fenton and biological treatment. Water Res 43(15):3838-3848. https://doi.org/ 10.1016/j.watres.2009.05.021

Bandala ER, Cossio H, Sánchez-Lopez AD, Córdova F, PeraltaHerández JM, Torres LG (2013) Scaling-up parameters for site restoration process using surfactant-enhanced soil washing coupled with wastewater treatment by Fenton and Fenton-like processes; decontamination of soil washing wastewater using solar driven advanced oxidation processes. Environ Technol 34(1-4):363-371. https://doi.org/10.1080/09593330.2012.696721 
Bavcon Kralj M, Fortuna A, Abram A, Trebše P (2020) Dish handwashing: an overlooked source of contamination. Environ Chem Lett 18(1):181-185

Bering S, Mazur J, Tarnowski K, Janus M, Mozia S, Morawski AW (2018a) The application of moving bed bio-reactor (MBBR) in commercial laundry wastewater treatment. Sci Total Environ 627:16381643. https://doi.org/10.1016/j.scitotenv.2018.02.029

Bering S, Mazur J, Tarnowski K, Dąbkowska N, Janus M, Mozia S, Morawski AW (2018b) Removal of organic pollutants and surfactants from laundry wastewater in membrane bioreactor (MBR). Desalin Water Treat 134:281-288. https://doi.org/10.5004/dwt. 2018.23207

Braga JK, Varesche MBA (2014) Commercial laundry water characterization. Am J Anal Chem 5:8-16. https://doi.org/10.4236/ajac.2014. 51002

Cabrera Reina A, Martínez-Piernas AB, Bertakis Y, Brebou C, Xekoukoulotakis NP, Agüera A, Sánchez Pérez JA (2018) Photochemical degradation of the carbapenem antibiotics imipenem and meropenem in aqueous solutions under solar radiation. Water Res 128:61-70. https://doi.org/10.1016/j.watres.2017.10.047

Collivignarellin MC, Miino MC, Baldi M, Manzi S, Abbà A, Bertanza G (2019) Removal of non-ionic and anionic surfactants from real laundry wastewater by means of a full-scale treatment system. Process Saf Environ 132:105-115. https://doi.org/10.1016/j.psep.2019.10. 022

Garrido-Cardenas JA, Esteban-García B, Agüera A, Sánchez-Pérez JA, Manzano-Agugliaro F (2020) Wastewater treatment by advanced oxidation process and their worldwide research trends. Int $\mathrm{J}$ Environ Res Public Health 17(1):170. https://doi.org/10.3390/ ijerph17010170

Hansson H, Kaczala F, Marques M, Hogland W (2012) Photo-Fenton and Fenton oxidation of recalcitrant industrial wastewater using nanoscale zero-valent iron. Int J Photoenergy 531076:1-11. https://doi. org/10.1155/2012/531076

Hinojosa Guerra MM, Oller Alberola I, Malato Rodriguez S, Agüera López A, Acevedo Merino A, Quiroga Alonso JM (2019) Oxidation mechanisms of amoxicillin and paracetamol in the photo-Fenton solar process. Water Res 156:232-240. https://doi. org/10.1016/j.watres.2019.02.055

Klavarioti M, Mantzavinos D, Kassinos D (2009) Removal of residual pharmaceuticals from aqueous systems by advanced oxidation processes: review. Environ Int 35:402-417. https://doi.org/10.1016/j. envint.2008.07.009

Koga M, Yamamichi Y, Nomoto Y, Irie M, Tanimura T, Yoshinaga T (1999) Rapid determination of anionic surfactants by improved spectrophotometric method using methylene blue. Anal Sci 15(6): 563-568. https://doi.org/10.2116/Analsci.15.563

Mahamallik P, Pal A (2017) Degradation of textile wastewater by modified photo-Fenton process: Application of $\mathrm{Co}(\mathrm{II})$ adsorbed surfactant-modified alumina as heterogeneous catalyst. J Environ Chem Eng 5(3):2886-2893. https://doi.org/10.1016/j.jece.2017.05. 044

Malakootian M, Jaafarzadeh N, Dehdarirad A (2016) Efficiency investigation of photo-Fenton process in removal of sodium dodecyl sulphate from aqueous solutions. Desalin Water Treat 57(51):24444 24449. https://doi.org/10.1080/19443994.2016.1140082

Malato S, Fernández-Ibáñez P, Maldonado MI, Blanco J, Gernjak W (2009) Decontamination and disinfection of water by solar photocatalysis: recent overview and trends. Catal Today 147(1):159. https://doi.org/10.1016/j.cattod.2009.06.018

Miklos DB, Hartl R, Michel P, Linden KG, Drewes E, Hübner U (2018) $\mathrm{UV} / \mathrm{H} 2 \mathrm{O} 2$ process stability and pilot-scale validation for trace organic chemical removal from wastewater treatment plant effluents.
Water Res 136:169-179. https://doi.org/10.1016/j.watres.2018.02. 044

Miralles-Cuevas S, Oller I, Agüera A, Sánchez Pérez JA, Malato S (2017) Strategies for reducing cost by using solar photo-Fenton treatment combined with nanofiltration to remove microcontaminants in real municipal effluents: Toxicity and economic assessment. Chem Eng J 318:161-170. https://doi.org/10.1016/j.cej.2016.06.031

Mirbahoush SM, Chaibakhsh N, Moradi-Shoeili Z (2019) Highly efficient removal of surfactant from industrial effluents using flaxseed mucilage in coagulation/photo-Fenton oxidation process. Chemosphere 231:51-59. https://doi.org/10.1016/j.chemosphere. 2019.05.118

Mozia S, Janus M, Brożek P, Bering S, Tarnowski K, Mazur J, Morawski AW (2016) A system coupling hybrid biological method with UV/ $\mathrm{O} 3$ oxidation and membrane separation for treatment and reuse of industrial laundry wastewater. Environ Sci Pollut Res Int 23:1914519155. https://doi.org/10.1007/s11356-016-7111-5

National Center for Biotechnology Information (n.d.) PubChem Database. Sodium dodecyl sulfate, CID $=3423265$, https:// pubchem.ncbi.nlm.nih.gov/compound/Sodium-dodecyl-sulfate (accessed 6 April 2020)

Patil VV, Gogate PR, Bhat AP, Ghosh PK (2020) Treatment of laundry wastewater containing residual surfactants using combined approaches based on ozone, catalyst and cavitation. Sep Purif Technol 239:116594. https://doi.org/10.1016/j.seppur.2020.116594

Pignatello JJ, Oliveros E, MacKay A (2006) Advanced oxidation processes for organic contaminant destruction based on the Fenton reaction and related chemistry. Crit Rev Environ Sci Technol 36:1-84. https://doi.org/10.1080/10643380500326564

Rahimpour R, Chaibakhsh N, Zanjanchi MA, Moradi-Shoeili Z (2020) Fabrication of $\mathrm{ZnO} / \mathrm{FeVO} 4$ heterojunction nanocomposite with high catalytic activity in photo-Fenton-like process. J Alloys Compd 817: 152702. https://doi.org/10.1016/j.jallcom.2019.152702

Soriano-Molina P, Plaza-Bolaños P, Lorenzo A, Agüera A, García Sánchez JL, Malato S, Sánchez Pérez JA (2019) Assessment of solar raceway pond reactors for removal of contaminants of emerging concern by photo-Fenton at circumneutral $\mathrm{pH}$ from very different municipal wastewater effluents. Chem Eng J 366:141-149. https:// doi.org/10.1016/j.cej.2019.02.074

Umar M, Aziz HA, Yusoff MS (2010) Trends in the use of Fenton, electro-Fenton and photo-Fenton for the treatment of landfill leachate. Review. Waste Manag 30(11):2113-2121. https://doi.org/10. 1016/j.wasman.2010.07.003

Yang CW, Wang D (2009) Effect of anionic surfactants on the process of Fenton degradation of methyl orange. Water Sci Technol 60:28032807. https://doi.org/10.2166/wst.2009.483

Yaseen ZM, Zigale TT, Tiyasha K, Ravi Kumar Q, Awasthi S, Tung TM, Al-Ansari N, Bhagat SK (2019) Laundry wastewater treatment using a combination of sand filter, bio-char and teff straw media. Sci Rep 9(1):18709. https://doi.org/10.1038/s41598-019-54888-3

Yu Y, Zhulei ZC, Zhiyuan C, Show G, Zhugi ZC (2015) Removal of refractory contaminants in municipal landfill leachate by hydrogen, oxygen and palladium: a novel approach of hydroxyl radical production. J Hazard Mater 287:349-355. https://doi.org/10.1016/j. jhazmat.2015.01.070

Zapata A, Velegraki T, Sánchez-Pérez JA, Mantzavinos D, Maldonado MI, Malato S (2009) Solar photo-Fenton treatment of pesticides in water: effect of iron concentration on degradation and assessment of ecotoxicity and biodegradability. Appl Catal B Environ 88(3-4): 448-454. https://doi.org/10.1016/j.apcatb.2008.10.024

Publisher's note Springer Nature remains neutral with regard to jurisdictional claims in published maps and institutional affiliations. 